\title{
Venous thrombosis and hormonal contraception: what's new with estradiol-based hormonal contraceptives?
}

This article was published in the following Dove Press journal:

Open Access Journal of Contraception

\section{Franca Fruzzetti ${ }^{1}$ \\ Angelo Cagnacci ${ }^{2}$}

'Department of Obstetrics and Gynaecology, Santa Chiara Hospital, University of Pisa, Pisa, Italy; ${ }^{2}$ Institute of Obstetrics and Gynecology, Department of Medical Area, University of Udine, Udine, Italy
Correspondence: Franca Fruzzetti Department of Obstetrics and Gynaecology, Santa Chiara Hospital, University of Pisa, Via Roma 35, 56100 Pisa, Italy

$\mathrm{Tel}+393297835816$

Fax +3905992 612

Email ffruzzi@tin.it
Objective: Estradiol (E2)-based hormonal contraceptives impact less than ethinylstradiol (EE) contraceptives on venous thromboembolism (VTE) in comparison to formulations with EE.

Study design: In this article, the pharamacologic data of EE and E2 were briefly reviewed, along with the induced biologic effect. These data were then related to a recent large international prospective, controlled, non-interventional cohort active surveillance study, on the cardiovascular risk of users of different types of combined estro-progestin contraceptive (CEPC).

Results: The crude HR for E2-valerate (E2V)/dienogest vs other CEPCs with EE was 0.8 (95\% CI, 0.4-1.6), but when the data were corrected for age, body mass index, duration of use, and family history of VTE, the corresponding adjusted HR was 0.5 (95\% CI, 0.2-1.0). A comparison of the E2V/dienogest and EE/levonorgestrel groups showed that the two contraceptives induced a similar VTE risk with the crude and adjusted VTE HRs of 0.7 (95\% CI, 0.3-1.8) and 0.5 (95\% CI, 0.2-1.3), respectively. Similar results were obtained when the observation was prolonged to January 2017.

Conclusions: The reduced impact of E2 vs EE on coagulation translates into the epidemiologic evidence of a reduced number of events in E2V vs EE users, when progestins other than levonorgestrel are used. However, E2 may continue to negatively impact on the risk of VTE, and this should not be forgotten at the time of prescription. Family history of VTE or thrombophilia, age, and obesity are risk factors for VTE too. If these risk factors are not taken into consideration and excluded, they can overcome or hide the higher safety of E2 vs CEPCs with EE.

Keywords: estradiol, estradiol valerate, contraception, venous thromboembolism, dienogest

\section{Introduction}

Venous thromboembolism (VTE) is rare among healthy women of reproductive age showing an incidence of 1-5 events per 10,000 women-years. ${ }^{1}$

The possible increase of venous thromboembolism causes concerns in oral contraceptives users and medical people too.

Oral and nonoral estro-progestin combined contraceptives (CEPC) increase the risk of VTE, including deep venous thromboembolism and pulmonary embolism (PE). ${ }^{2,3}$ The risk is low (less than 5-12 events per 10,000 women-years of exposure) and lower than the VTE risk observed during pregnancy and in the postpartum period. ${ }^{4,5}$ Nevertheless, the possible increase of VTE during CEPCs causes concern in the scientific community, physicians, and users of hormonal contraceptives. The risk of venous thromboembolism is dependent on the effect of estrogens on coagulation. Two different estrogens are nowadays used in CEPCs: estradiol (E2) (either 
micronized or valerate) and ethynylestradiol (EE). For many years EE has been the only estrogen present in CEPCs because it is more potent and has a better oral bioavailability $(38 \%-48 \%)$ than other estrogens. ${ }^{6}$ When administered, EE increases procoagulatory factors and decreases anticoagulatory mechanisms, ${ }^{7,8}$ inducing a dose-related increase of VTE. ${ }^{9-11}$ Introduction in the market of low-dose CEPCs (containing $<50 \mu \mathrm{g}$ or less EE) led to a reduced risk of VTE, ${ }^{12,13}$ which, however, remained consistent even with very low EE doses $(20 \mu \mathrm{g})$ or with the use of non-oral routes of administration (transdermal or vaginal). ${ }^{14}$

In the mid-1990s, several studies indicated that lowdose CEPCs containing a combination of $30 \mu \mathrm{g}$ EE and 150 $\mu \mathrm{g}$ desogestrel had a risk of VTE higher than those containing $30 \mu \mathrm{g}$ EE and $150 \mu \mathrm{g}$ levonorgestrel. ${ }^{12,15-17}$ Because desogestrel per se, administered as progestin-only contraceptive, does not show any procoagulant effect and does not increase the risk of VTE, ${ }^{18}$ the reported increased VTE risk of EE-desogestrel vs EE-levonorgestrel can only be attributed to a different modulation of the procoagulatory effect of EE, exerted by the two progestins. Indeed, progestins may counteract the procoagulant effects of estrogen to varying degrees. In fact, many studies indicated that some progestogens, particularly those with a high androgenic potency, antagonize more than others the risk of VTE associated with EE. ${ }^{12,15-17}$ Accordingly, the risk of VTE of the general population increases two- to threefold in users of CEPCs containing EE associated with norethisterone, levonorgestrel, or norgestimate, ${ }^{2,9}$ and of sixfold in users of CEPCs containing desogestrel, gestodene, drospirenone, or cyproterone acetate. ${ }^{2,9,12,15-17}$

Menstrual irregularities reduce acceptance of CEPCs with doses of EE below $15 \mu \mathrm{g},{ }^{19}$ but yet procoagulant effects of EE are reported also with doses of $10 \mu \mathrm{g}$. Accordingly, it is unlikely that the risk on VTE can be overcome by reducing the doses of EE contained in CPECs.

In 2009, CPECs containing E2 in the place of EE were marketed.

\section{Methods}

In this article, the possible advantages of using E2-based CPECs, in particular on VTE, were briefly reviewed. Briefly, the pharmacologic data on E2 and EE were reviewed and presented in conjunction with the biologic effect. This evaluation was preliminary to interpret new epidemiologic evidence on the cardiovascular risk associated with E2- vs EE-based CPECs.

\section{Results}

\section{E2 versus EE: pharmacologic effects}

Exogenously administered E2 is chemically identical to endogenous $17 \beta$-estradiol, the most potent natural estrogen produced by the ovary. Because of its low oral bioavailability (5\%), ${ }^{20}$ the place of E2 in CPECs was taken by EE whose oral bioavailability was $38 \%-48 \% .{ }^{21}$ Micronization and esterification enhanced oral bioavailability of E2,22 allowing its use in contraception. E2-valerate $(\mathrm{E} 2 \mathrm{~V})$, the valerate ester of E2, is rapidly converted to $\mathrm{E} 2$ in the gut and liver, ${ }^{23}$ and it has a pharmacokinetic profile similar to E2. E2 is converted to estrone by the activity of 11 beta-hydroxylase. Because estrone can be reconverted, it represents a circulating reservoir for E2, allowing fairly stable E2 levels following oral E2V administration. ${ }^{24}$

\section{E2 versus EE: biologic effects}

E2 impacts less than EE on metabolic and hepatic parameters as documented by its neutral effect on lipids and its blunted effect on hepatic proteins, such as sex hormonebinding globulin and angiotensinogen. ${ }^{25} \mathrm{~A}$ consequence of this reduced effect is its neutrality on blood pressure that instead is increased by EE-based CEPCs. ${ }^{26,27}$ In spite of the fact that CEPCs with E2 are marketed with non-androgenic progestins, their effect on various hemostatic parameters is similar or lower than that induced by CEPCs containing androgenic progestins (levonorgestrel) associated with EE, and lower than that exerted by the association of $\mathrm{EE}$ and nonandrogenic progestins. ${ }^{28-32}$

These reassuring results on the coagulatory mechanisms were recently confirmed by epidemiologic evidence.

\section{E2 versus EE: epidemiologic evidence}

The INAS-SCORE, a large international prospective, controlled, noninterventional cohort active surveillance study, investigated the occurrence of VTE and other cardiovascular events over a 3- to 5-year period in E2V/dienogest and other EE-containing CEPC users. The study started to recruit in 2009 up to 2012 . First analysis was published in $2016 .{ }^{33}$ The last follow-up study was performed in 2017, and the results recently adjourned. ${ }^{34}$ The first results of the INAS score study that were published in 2016 were based on 50,203 new CEPC users followed up for to 5.5 years (mean value, 2.1 years). ${ }^{33}$ Overall, $20.3 \%$ of these women had used E2V/dienogest, and $79.7 \%$ other CEPCs (including $11.5 \% \mathrm{EE} /$ levonorgestrel). Seventy-seven VTE were documented, of which only $1 / 3$ 
with a severe clinical manifestation, such as PE (26 out of 77 VTE cases; 34\%).

The rate of VTE during E2V/dienogest (7.2 VTE per 10,000 women-years [WY]), oral CEPCs (9.1 VTE per 10,000 WY), and EE with levonorgestrel (9.9 VTE per 10,000 WY) was higher than in "no use" group (3.5 VTE per 10,000 WY).

The crude HR for E2V/dienogest vs other CEPCs was 0.8 (95\% CI, 0.4-1.6), but it became significant when the data were corrected for age, body mass index (BMI), duration of use, and family history of VTE (adjusted HR was 0.5 [95\% CI, 0.2-1.0]). Vice versa, the risk of VTE was similar in users of E2V/dienogest and EE/levonorgestrel with a crude HR of 0.7 (95\% CI, 0.3-1.8) and an adjusted HR of $0.5(95 \%$ CI, 0.2-1.3).

Low adherence in the USA users prompted to a subanalysis of the INAS-SCORE performed only in the European countries with a prolongation of the observation. ${ }^{33}$ In this subanalysis, results did not change. The crude HR of VTE for E2V/dienogest vs other CEPCs was 0.9 (95\% CI, 0.4-1.8), but it became significant (adjusted HR of 0.4 with an upper $95 \%$ confidence limit of 0.98 ) when corrected for confoundings. The comparison of the E2V/dienogest and EE/ levonorgestrel confirmed the same risk of VTE between the two, with a crude and adjusted HR for VTE of 0.8 (95\% CI, $0.3-2.4)$ and 0.5 (95\% CI, 0.2-1.5), respectively.

The extension phase was performed with the last patient at follow-up finalized in January 2017. ${ }^{34}$ At the end, 69,888 WY CEPCs exposure was analyzed. Data were limited to those obtained in Europe only. The VTE incidence was 7.1/10,000 WY for EV/dienogest and 8.8/10,000 WY, for other CEPCs including pills with EE/levonorgestrel. The crude HRs for EV/dienogest vs other CEPCs and EE/levonorgestrel pills were 0.9 and 0.8 but the difference did not reach the statistical significance. When the data were corrected for age, BMI, duration of use, and family history, the HR for VTE of E2V/dienogest was significantly lower in comparison to all CEPCs (HR 0.4; 95\% CI, 0.2-0.9), but not in comparison to EE/levonorgestrel pill.

\section{Discussion}

Given the popularity and widespread use of CEPCs, any increase in the relative risk of VTE associated with a particular CEPC formulation could translate into an important increase in absolute numbers. Nevertheless, the risk, which may be substantial (up to sixfold), multiplies a baseline risk that in the case of fertile women, particularly in young age, is very low. In the worst of the scenarios, it is assumed that the use of CPECs can cause an increase of about 1-1.2 VTE over 1000 exposed women per year. As the consequence, the documented clinical variances among the different CPECs formulations should be confronted with the possibility to increase of 0.5 or $1.0 \mathrm{VTE}$ over 1000 women per year. Clinicians, whose main focus is to increase the risk of not more than $0.5 \mathrm{VTE}$ per 1000 women year, were left with only one option, the association of EE and a strong androgenic progestin. Those more concerned of individualization used also other CEPCs, taking the risk of increasing VTE rate of 1.0/1000 women per year. Nowadays, epidemiologic evidence supported by biochemical and pharmacologic data indicates that EE and androgenic progestins are not the only option for minimizing the risk of VTE associated with CEPCs use, but that E2V/dienogest is as safe as EE/levonorgestrel. ${ }^{33,35}$ Risk factors such as age, obesity, cigarette smoking, genetic predisposition, or familiar history of VTE may contribute to increase the risk of VTE, ${ }^{36}$ and to the final risk of VTE during CEPC use. In the INAS-SCORE, it was possible to correct for some of these confoundings, ultimately revealing a lower risk of VTE associated to E2V/dienogest than other CEPCs. These data stimulate two considerations: E2V/dienogest was already perceived by physicians and women as safer than other CEPCs, and accordingly, it was prescribed and used by women with a higher risk of VTE; E2V/dienogest was indeed safer than most other CEPCs, because when the data were corrected for known risk factors for VTE, it was associated with a lower VTE risk. Nevertheless, CEPCs containing E2 continue to negatively impact on coagulation. This should not be forgotten at the time of prescription. In the women with VTE risk factors, E2-based CEPCs do not represent a valid alternative to progestin-only contraceptives. ${ }^{36}$

\section{Conclusion}

In the case of E2-based CEPCs, the pharmacologic data and the modifications of surrogate markers correspond to the epidemiologic evidence. The reduced impact of E2 vs EE on coagulation translates into the epidemiologic evidence of a reduced number of events in E2V vs EE users, when progestins other than levonorgestrel are used. Accordingly, CEPCs with E2 may significantly reduce the overall VTE burden linked to the use of contraception and be used in place of EE/levonorgestrel. Indications to using an E2 can be various. Among these an eye should be directed to the preliminary data showing a tendency of a reduced risk of arterial thromboembolism in E2V/dienogest vs EE/levonorgestrel users (HR 0.1; 95\% CI, 0.0-1.2). ${ }^{33}$ The lack of attention at 
the time of prescription to risk factors may hide the higher safety of E2-based CEPCs.

\section{Acknowledgment}

The authors thank Mr Bob Lermont for his assistance in language revision.

\section{Author contributions}

All authors meet the criteria listed in the author guidelines. All authors contributed to data analysis, drafting or revising the article, gave final approval of the version to be published, and agree to be accountable for all aspects of the work.

\section{Disclosure}

The authors report no conflicts of interest in this work.

\section{References}

1. Ageno W, Squizzato A, Garcia D, Imberti D. Epidemiology and risk factors of venous thromboembolism. Semin Thromb Hemost. 2006;32(7):651-658.

2. Dragoman MV, Tepper NK, Fu R, Curtis KM, Chou R, Gaffield ME. A systematic review and meta-analysis of venous thrombosis risk among users of combined oral contraception. Int J Gynaecol Obstet. 2018;141(3):287-294.

3. Stegeman BH, de Bastos M, Rosendaal FR, et al. Different combined oral contraceptives and the risk of venous thrombosis: systematic review and network meta-analysis. BMJ. 2013;347:f5298.

4. Committee on Gynecologic Practice. ACOG Committee Opinion Number 540: Risk of venous thromboembolism among users of drospirenone-containing oral contraceptive pills. Obstet Gynecol. 2012;120(5): 1239-1242.

5. McLean K, Cushman M. Venous thromboembolism and stroke in pregnancy. Hematology Am Soc Hematol Educ Program. 2016;2016(1):243-250.

6. Krattenmacher R, Knauthe R, Parczyk K, Walker A, Hilgenfeldt U, Fritzemeier KH. Estrogen action on hepatic synthesis of angiotensinogen and IGF-I: direct and indirect estrogen effects. J Steroid Biochem Mol Biol. 1994;48(2-3):207-214.

7. Cagnacci A. Hormonal contraception: venous and arterial disease. Eur J Contracept Reprod Health Care. 2017;22(3):191-199.

8. Fruzzetti F, De Negri F, Morale M, et al. Activation of coagulation in smoking and non-smoking women using a third-generation oral contraceptive containing desogestrel. Eur J Contracept Reprod Health Care. 1999;4(3):113-118.

9. van Hylckama Vlieg A, Helmerhorst FM, Vandenbroucke JP, Doggen CJ, Rosendaal FR. The venous thrombotic risk of oral contraceptives, effects of oestrogen dose and progestogen type: results of the MEGA case-control study. BMJ. 2009;339:b2921.

10. Lidegaard Ø, Løkkegaard E, Svendsen AL, Agger C. Hormonal contraception and risk of venous thromboembolism: national follow-up study. BMJ. 2009;339:b2890.

11. Peragallo Urrutia R, Coeytaux RR, McBroom AJ, et al. Risk of acute thromboembolic events with oral contraceptive use: a systematic review and meta-analysis. Obstet Gynecol. 2013;122(2 Pt 1):380-389.

12. Lidegaard Ø, Nielsen LH, Skovlund CW, Skjeldestad FE, Løkkegaard E. Risk of venous thromboembolism from use of oral contraceptives containing different progestogens and oestrogen doses: Danish cohort study, 2001-2009. BMJ. 2011;343:d6423.

13. Böttiger LE, Boman G, Eklund G, Westerholm B. Oral contraceptives and thromboembolic disease: effects of lowering oestrogen content. Lancet. 1980;1(8178):1097-1101.

14. Lidegaard O, Nielsen LH, Skovlund CW, Løkkegaard E. Venous thrombosis in users of non-oral hormonal contraception: follow-up study, Denmark 2001-10. BMJ. 2012;344:e2990.
15. Venous thromboembolic disease and combined oral contraceptives: results of international multicentre case-control study. World Health Organization Collaborative Study of Cardiovascular Disease and Steroid Hormone Contraception. Lancet. 1995;346(8990):1575-1582.

16. Jick H, Jick SS, Gurewich V, Myers MW, Vasilakis C. Risk of idiopathic cardiovascular death and nonfatal venous thromboembolism in women using oral contraceptives with differing progestagen components. Lancet. 1995;346(8990):1589-1593.

17. Spitzer WO, Lewis MA, Heinemann LA, Thorogood M, MacRae KD. Third generation oral contraceptives and risk of venous thromboembolic disorders: an international case-control study. Transnational Research Group on Oral Contraceptives and the Health of Young Women. BMJ. 1996;312(7023):83-88.

18. Tepper NK, Whiteman MK, Marchbanks PA, James AH, Curtis KM. Progestin-only contraception and thromboembolism: a systematic review. Contraception. 2016;94(6):678-700.

19. Gallo MF, Nanda K, Grimes DA, Schulz KF. 20 mcg versus $>20$ mcg estrogen combined oral contraceptives for contraception. Cochrane Database Syst Rev. 2005;(2):CD003989.

20. Kuhnz W, Gansau C, Mahler M. Pharmacokinetics of estradiol, free and total estrone, in young women following single intravenous and oral administration of 17 beta-estradiol. Arzneimittelforschung. 1993;43(9):966-973.

21. Kuhl H. Pharmacology of estrogens and progestogens: influence of different routes of administration. Climacteric. 2005;8(Suppl 1):3-63.

22. Kuhnz W, Blode H, Zimmermann H. Pharmacokinetics of exogenous natural and synthetic estrogens and antiestrogens. In: Oettel M, Schillinger E, editors. Handbook of Experimental Pharmacology, Estrogens and Antiestrogens II. Berlin: Springer Verlag; 1999:261-322.

23. Düsterberg B, Nishino Y. Pharmacokinetic and pharmacological features of oestradiol valerate. Maturitas. 1982;4(4):315-324.

24. Zeun S, Lu M, Uddin A, Zeiler B, Morrison D, Blode H. Pharmacokinetics of an oral contraceptive containing oestradiol valerate and dienogest. Eur J Contracept Reprod Health Care. 2009;14(3): 221-232.

25. Kuhl H. Adverse effects of estrogen treatment: natural versus synthetic estrogens. In: Lippert TH, Mueck AO, Ginsburg J, editors. Sex Steroids and the Cardiovascular System. New York: The Parthenon Publishing Group; 1996:201-221.

26. Grandi G, Xholli A, Napolitano A, Piacenti I, Bellafronte M, Cagnacci A. Prospective measurement of blood pressure and heart rate over $24 \mathrm{~h}$ in women using combined oral contraceptives with estradiol. Contraception. 2014;90(5):529-534.

27. Conard J, Basdevant A, Thomas JL, et al. Cardiovascular risk factors and combined estrogen-progestin replacement therapy: a placebocontrolled study with nomegestrol acetate and estradiol. Fertil Steril. 1995;64(5):957-962.

28. Junge W, Mellinger U, Parke S, Serrani M. Metabolic and haemostatic effects of estradiol valerate/dienogest, a novel oral contraceptive: a randomized, open-label, single-centre study. Clin Drug Investig. 2011;31(8):573-584.

29. Klipping C, Duijkers I, Parke S, Mellinger U, Serrani M, Junge W. Hemostatic effects of a novel estradiol-based oral contraceptive: an open-label, randomized, crossover study of estradiol valerate/dienogest versus ethinylestradiol/levonorgestrel. Drugs R D. 2011;11(2):159-170.

30. Ågren UM, Anttila M, Mäenpää-Liukko K, et al. Effects of a monophasic combined oral contraceptive containing nomegestrol acetate and $17 \beta$-oestradiol compared with one containing levonorgestrel and ethinylestradiol on haemostasis, lipids and carbohydrate metabolism. Eur J Contracept Reprod Health Care. 2011;16(6):444-457.

31. Gaussem P, Alhenc-Gelas M, Thomas JL, et al. Haemostatic effects of a new combined oral contraceptive, nomegestrol acetate/17 $\beta$-estradiol, compared with those of levonorgestrel/ethinyl estradiol. A double-blind, randomised study. Thromb Haemost. 2011;105(3):560-567.

32. Raps M, Rosendaal F, Ballieux B, et al. Resistance to APC and SHBG levels during use of a four-phasic oral contraceptive containing dienogest and estradiol valerate: a randomized controlled trial. J Thromb Haemost. 2013;11(5):855-861. 
33. Dinger J, Do Minh T, Heinemann K. Impact of estrogen type on cardiovascular safety of combined oral contraceptives. Contraception. 2016;94(4):328-339.

34. Heinemann K, Franke C, Moehner S, do Minh T, Dinger J. Cardiovascular safety in users of different combined oral contraceptives - Final results from the INAS-SCORE study Abstract FC-03, Book of abstracts: 15 th Congress of the European Society of Contraception and Reproductive Health. Eur J Contracept Reprod Health Care. 2018;23:1-143.
35. Dinger J, Bardenheuer K, Heinemann K. Cardiovascular and general safety of a 24-day regimen of drospirenone-containing combined oral contraceptives: final results from the International Active Surveillance Study of Women Taking Oral Contraceptives. Contraception. 2014;89(4): 253-263.

36. Cushman M. Epidemiology and risk factors for venous thrombosis. Semin Hematol. 2007;44(2):62-69.
Open Access Journal of Contraception

\section{Publish your work in this journal}

Open Access Journal of Contraception is an international, peerreviewed, open access, online journal, publishing original research, reports, reviews and commentaries on all areas of contraception. In addition to clinical research, demographics and health-related aspects, the journal welcomes new findings in animal and preclinical studies

\section{Dovepress}

relating to understanding the biological mechanisms and practical development of new contraceptive agents. The manuscript management system is completely online and includes a very quick and fair peer-review system. Visit http://www.dovepress.com/testimonials.php to read real quotes from published authors.

Submit your manuscript here: https://www.dovepress.com/open-access-journal-of-contraception-journal 